\section{MOSQUITO WORK IN RELATION TO YELLOW FEVER ON THE ISTHMUS OF PANAMA.*}

\author{
W. C. GORGAS, M.D.
}

Colonel and Assistant Surgeon-General of the United States Army and Chlef Sanitary OGicer, Canal Zone.

ANCON, CANAL ZONE.

I shall confine myself more particularly to the question of yellow fever and malarial fever. While we have to deal with all tropical diseases on the Isthmus and to establish a health department such as any community of the same size in temperate zones would be obliged to have, these two diseases, yellow fever and malaria, wcre the great ones that had caused the principal mortality in the two great works before undertaken down there, namely, the building of the railroad and the attempted construction of the canal by the French. The conditions were much the same as had confronted us in Havana, with the exception that in Cuba we had for two months in the year cool weather during which mosquitoes bred searcely at all ; in Panama there is no difference of season except that between the wet and dry season, and mosquitos breed as readily in January as in July. Another difference is that at Panama we have a country district of 50 miles in extent to guard against malaria troubles; in Havana we merely had the suburbs of the city to attend to in this respect.

During the French occupation the heavy mortality among their European employés had been a potent factor in the failure of the canal work. It is difficult for us to get statistics that represent exactly the losses under the French. Their work was done under the contract system, the canal line having been divided up into seventeen divisions and let to seventeen different contractors. These contractors were charged a dollar a day for every sick man to be taken care of in the hospitals of the French company. The tendency would be, therefore, when a man became sick for his employer to discharge him so that he would not have to bear the expense of his care. The French company were building a canal through the Columbian territory, just as the Pennsylvania Railroad built its track through Pennsylvania; they had no police control whatever of the territory along the canal. They had no means of telling how many of these employés of the contractors died along the line. All that they could know was that so many reported for work each day; what became of the others they had no means of telling. At their large hospital, Ancon, they kept very accurate statistics, and the number of deaths that occurred there can be safely quoted as entirely correct, but it leaves a very great limit of uncertainty as to what portion were treated in hospital and what proportion died along the line. The English consul, who was down there during the period of construction, is inclined to think that more deaths of employés occurred out of the hospital than in it, and he had very good opportunities for judging. Nine-tenths of the laborers were Jamaica negroes, English subjects, and looked to the English consul for care and protection. The consul tells me that he personally knows of a great many being found dead along the roadside while endeavoring to find their way to him in the City of Panama, and some even dying in his office. On the other hand, the old French superintendent of hospital, Dr. La Croisade, who is still with us, thinks that the hospital statistics represent most of the deaths.

* Address delivered before the American Soclety of Tropical Medicine, nec. 8, 1905 .
It seems to me, both from what I can find out as common opinion on the Isthmus, and what would seem to me to be human nature under the circumstances, that it is a fair conclusion that the French statistics represent not more than half the mortality that actually occurred. And in quoting these statistics I will ask that this be borne in mind.

The United States Government took over the canal property in May, 1904, but for various reasons there was considerable delay in getting sanitary work fully started, and the authority for doing 'sanitary work in the towns of Colon and Panama was not granted till toward the latter part of February, 1905. We then built up much the same organization here that we had developed in $\mathrm{Ha}-$ vana. All cases of yellow fever were required to be reported to the American health authorities, and in addition to this, all cases of fever of any kind occurring in an American were also required to be reported. It was a considerable advantage to us in Panama that the equipment of our hospital allowed us to give very much better nursing, care and medical attention to all patients than could be obtained elsewhere on the Isthmus. For this reason, Americans generally reported to the hospital when they had fever of any kind, and we usually got cases of yellow fever within the first day or two of the disease. This resulted favorably to the patient as well as to the sanitary authorities; while the general mortality was about 25 per cent. of all cases, the mortality of the Americans treated in our hospitals was not more than 10 per cent.

As soon as we took possession of the hospital, we had two wards thoroughly screened and equipped for keeping out mosquitos, just as had been our wards in Havana. The suspected patient, when brought up, was placed in one of these wards. It is interesting to see what entire confidence all of our people soon acquired in the mosquito theory of the transmission of this disease. Ancon Hospital is beautifully situated on the side of the Ancon Mountain overlooking the City of Panama and the Pacific Ocean. It is pleasantly laid out in graded roads and paths beautified with tropical shrubbery of all kinds, and embowered in a grove of rubber trees and royal palms. Twenty years ago, under the French, it soon became infested with yellow fever, and every poor Frenchman who came in from whatever cause contracted yellow fever, and more than half of those who contracted this disease died. I was informed through the old superintendent who was in charge at the time, that in one day they lost from yellow fever three of their medical staff and in the same month nine of the same body. Of the 36 sisters whom they brought over as female nurses, 24 died of yellow fever. One of the chiefs of our supply department who came over in the early French days told me that he was one of 18 young French engineers who came over in one vessel; that in a month after their arrival all had died but himself. I am merely mentioning these details to show how different the circumstances are at present.

For nearly two years now we have constantly had yellow fever in these wards; the nurses and physicians are all non-immunes, yet not a single case of yellow fever has been contracted in this way. The nurses never seemed to consider that they were running any risk in being with yellow fever cases night and day in these screened wards, and the wives and families of the officers connected with the hospital lived about the grounds in all directions with the knowledge that yellow fever is constantly being brought into the grounds and treated in the buildings contiguous to them. I do not say this at all in criticism of the French. Under the same circum- 
stances twenty-four years ago I doubt if we could have done any better, but the knowledge acquired by Peed's board and Finley's persistent propaganda, have enabled us absolutely to exclude all probability of any contraction of the disease in our hospital. An American sick from any cause at Panama has no fear whatever of being treated in the bed next to that in which his companion is being treated for yellow fever. Dr. Carter and I live in the old ward used by the French for their officers. In this building, I suppose it is safe to say, more men have died from yellow fever than in any other building of the same bed capacity at present standing. We have our wives and children with us. Ten years ago I would have thought this the height of recklessness, but to-day, by taking precautions which are now recognized in yellow-fever work, we all look on ourselves almost as safe as we would be here in Philadelphia. In the yellowfever wards the additional precaution is taken of putting each new patient in a wire cage just large enough to cover his bed. Here he is kept until the infectious period of the disease has been passed. Of course, in so important a matter as treating yellow fever in a general hospital, no possible chance of the spread of infection can be taken, so that in addition to every possible measure for keeping mosquitoes out of the ward and away from the yellow-fever patients, we also fumigate these wards every two weeks, so that if a mosquito should get in and bite a patient she would not have time to become herself infected. You will recollect that a period of time of from twelve to fifteen days has to elapse from the time that the female stegomyia bites the yellow-fever patient till she herself becomes infected and is able to convey the disease; therefore, if we fumigate every two weeks we would catch all mosquitoes before they had time to do harm.

The case having been reported in the city and the patient having been removed in a screened ambulance to the hospital, orders would be given from the central health office to the proper fumigating brigade to fumigate this house and all the contiguous houses, with the intention of killing the mosquitoes who gave the disease and also those that had bitten the yellow-fever patient, and if left alone would become dangerous in a couple of weeks. The stegomyia is a very domestic mosquito and generally does not leave the house where she is born and bred and does not stir much from the room where she has lived; probably the fumigation of the house itself would catch all infected mosquitoes, but as an additional precaution the contagious houses were taken, so that if by accident an infected mosquito ha.l drifted from her original locality, she would be caught. The fumigating squads were composed of an experienced foreman and twenty men. They carefully pasted the house just as one would if one were going to disinfect with formalin. The fumigating material generally used was sulphur, sulphur being decidedly the best mosquitocide we have, but in many buildings, such as stores and the better class of residences, there are many articles that are seriously injured by sulphur. In such cases we see Persian insect powder, pyrethrum; but in the use of pyrethrum care has to be taken that the mosquitoes are swept up and destroyed immediately after the fumigation. If this precaution is not taken a few may revive and again become dangerous. The patient is not forced to go to the hospital if he does not so desire. If he elects to be treated at home, the central office is so informed and the carpenter squad, who have screens on hand prepared for this purpose, are ordered down and screen the patient in so that he is protected from mosquitoes and those that are in the room can not get out. Only one exit is left the room, a guard is placed who keeps the key of the door and only allows those in and out who are authorized by the physician. The fumigation in the rest of the house is then finished and the screened room is fumigated when the case has terminated.

As I have just stated, the stegomyia is a very domestic mosquito. She is very cleanly in her habits and breeds principally in clean rain water. In Panama the population have depended principally on rain water for domestic purposes, so that every house had cisterns, water barrels and such receptacles for catching and storing rain water. These we had to cover so that mosquitoes could not have access to them; for this purpose the city was divided up into small districts with an inspector in charge of each district. This inspector is required to get around his district at least twice a week, and make a report on each building with regard to its condition as to mosquito breeding. All the cisterns and water containers in Panama have now been covered and in the water barrels spigots so placed that the covers do not have to be taken off when water is drawn. About the first of March, when the first inspections were made, in the neighborhood of 4,000 breeding places were reported. On the last of October, when the last inspection was reported just before I left Panama, less than 400 receptacles containing larvæ were recorded. This, I think, will give you a fair idea of the decrease in mosquitoes through the City of Panama.

In the City of Panama we found by count that 90 per cent. of the mosquitoes were stegomyia. This is another point in which we greatly differed from Havana. In Havana we found by count that only about 5 per cent. of the mosquitoes were stegomyia. This about covers the ground of the methods adopted for controlling yellow fever. Of course, you can see how very important it is for us to get hold of every case of ycllow fever as it occurs; particularly is this the case at present, when it has about disappeared. The governor has offered a reward of $\$ 100$ for any case of yellow fever reported to the authorities. Between Panama and Colon there are some twenty villages running from 500 inhabitants up to 3,000 ; yellow fever in the last year has occurred at several of these villages. A queer thing about yellow fever is the fact that the natives in a locality where it frequently occurs are entirely immune, and not liable to contract a disease, so that in these small towns it is only the American employe who can have yellow fever. They usually live in frame buildings, well separated from the surrounding buildings, and it is a very simple thing to fumigate such buildings at once when a case occurs, and to get rid of the disease. We have not had a single instance of failure in disinfection in any of these small towns.

The results of this work have been the apparent elimination of yellow fever. In June, on the zone, we had 67 cases, in July 40 odd cases, in August about 27 cases, in September about 7 cases, in October 3 cases, and none in November and none so far in December. In the town of Colon our last case occurred July 23. Of course, it would be too early to say that yellow fever had been entirely eradicated from the Isthmus. This can not be affirmed with any certainty until the full life of a female stegomyia mosquito has been passed since the last case. In Havana, at Las Animas, we had a female stegomyia mosquito live in captivity for 150 days. So I think we ought to let at least two months pass without a case before we can say with any certainty that yellow fever has been eliminated. The same measures for the control 
of yellow fever and the extermination of the stegomyia mosquito were taken at Colon and at the various places along the line of the canal. While yeliow fever has a great moral effect on the force, and was more important from this point of view to us than any other disease, malaria was the disease that had always caused the greatest loss from disability, that is, in a large force of men more days were lost from work on account of malaria than probably from all other disease put together.

My paper has already extended to such lengths that I can not go into a detailed description of the measures taken against malaria. They were the same as those outlined at Havana, and that are now so generally in use in the United States, principally superficial ditching. The results have been as satisfactory as they were in Cuba. In October we had a force of 22,000 men on our pay roll; of this number 21 per thousand were sick daily. This is an exceptionally small sick rate, very much less than is the average for our army in the Philippines. I think it safe to say that we are now digging the canal with as little trouble from sickness as would be the case if a similar number of men were engaged in a similar project between Philadelphia and Batlimore, and I see no reason why this rate should not be continued or even improved on. Water supplies are being put in, sewage systems constructed, houses repaired and built, food supplies and cooking arrangements constantly improved.

\section{MEDICAL FORGERIES.}

\section{S. D. VAN METER, M.D. DENVER.}

It is fortunate for society that most of us are not familiar with the many disheartening pages of criminology, because we experience sufficient disappointments early in life to shake the most optimistic faith in

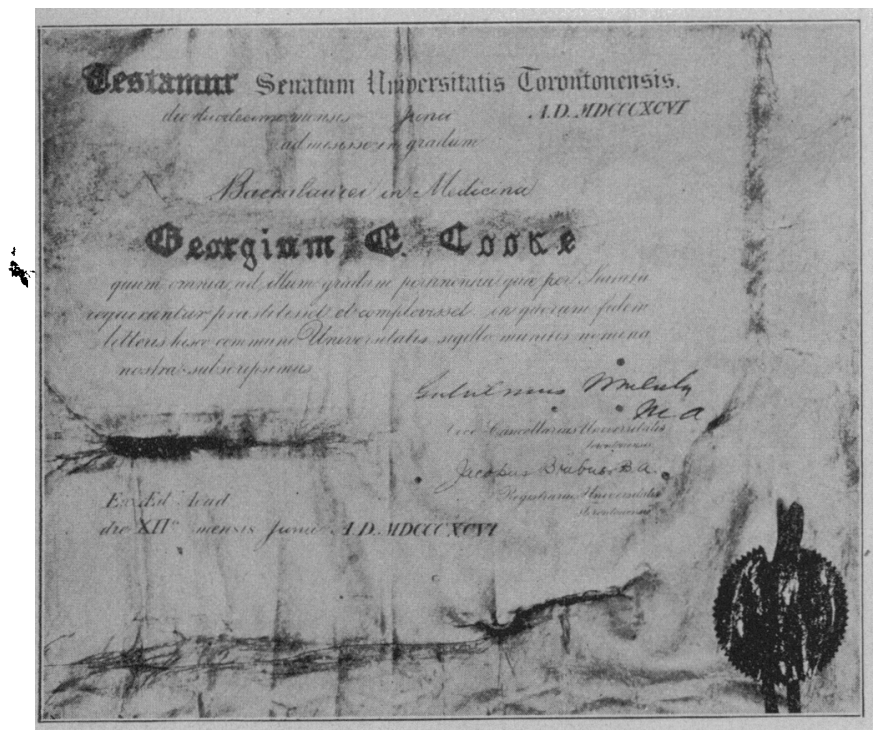

Fig. 1.-AItered diploma of George A. Llliott. Identification is unquestionable, as it bears the Colorado Registration Board's Inspection mark on its reverse side. This document was hanging In Ryetzel's offce when arrested In Chicago by the federal authoritles.

human nature; but there are certain phases of moral perversion of which but little is known to the expert criminologist, much less to the general masses. Untrodden ground is always interesting, and especially so if publicity of the unknown discovered there can benefit mankind.
The study of the many medical forgeries and frauds that are perpetrated on the unsuspecting public throughout the world, but more especially in this country, where our laws regulating the practice of medicine are so ineffective, offers a field for investigation replete with examples of moral turpitude comparatively unknown to the medical profession and of which the general public has no conception. If such were not true public opinion relative to the suppression of charlatanry would not be what it is to-day. When a traveler is relieved of his purse by the highwayman the people are up in arms and ready to mete out the death punishment without aid of court or jury. How different is the situation when those entrusted with the administration of our medical laws try to punish these robbers of the credulous sick!

The public is prone to assume, without investigation, that the medical boards are prompted by professional spite and jealousy in such prosecutions; and without the support of public sentiment the best law is seldom operative. It seems incredible that any one could be so

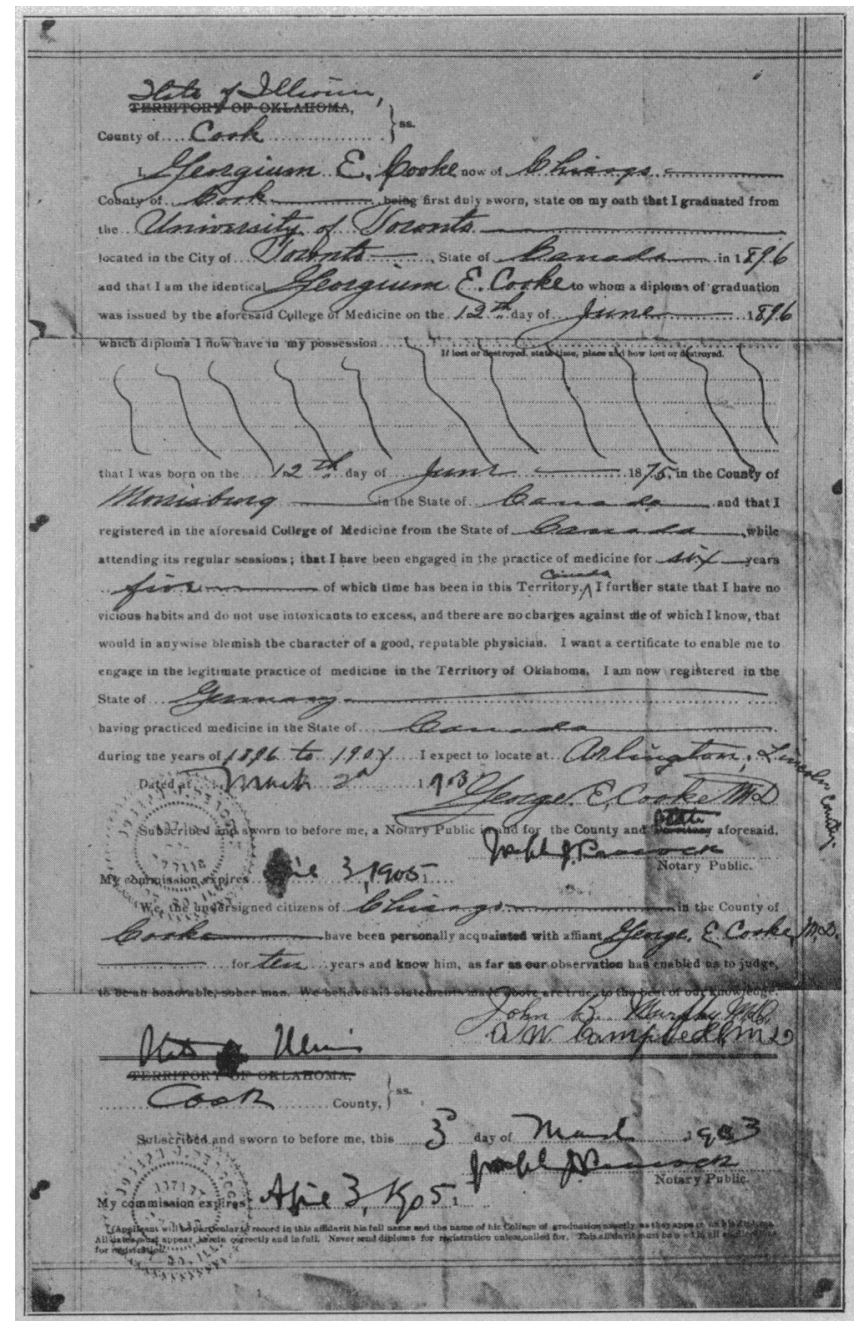

Fig. 2.-Forged application affidavit used by Ryetzel under the allas of Cooke to secure a license in Oklahoma. The signature of John B. Murphy is in the handwriting of Marietta Inman. Ryetzel's last wife.

thoughtless in the exercise of Nature's first law, selfpreservation, not to use every effort possible to prevent the criminally inclined from entering a field where, when legally installed, he has the opportunity to deceive and prey on the ignorant and educated alike with but little fear of detection. 